\title{
Different B cell subpopulations show distinct patterns in their IgH repertoire metrics
}

\section{Marie Ghraichy ${ }^{1}$, Valentin von Niederhäusern ${ }^{1}$, Aleksandr Kovaltsuk ${ }^{2}$, Jacob D Galson ${ }^{1,3}$, Charlotte M Deane ${ }^{2}$, Johannes Trück ${ }^{1 *}$}

1'Division of Immunology, University Children's Hospital and Children's Research Center, University of Zurich (UZH), Zurich, Switzerland; '2Department of Statistics, University of Oxford, Oxford, United Kingdom; ${ }^{3}$ Alchemab Therapeutics Ltd, London, United Kingdom
*For correspondence: Johannes.Trueck@kispi.uzh.ch Competing interest: See page 12

Funding: See page 12

Received: 17 August 2021

Preprinted: 05 September 2021

Accepted: 17 October 2021

Published: 18 October 2021

Reviewing Editor: Tomohiro Kurosaki, Osaka University, Japan

(c) Copyright Ghraichy et al. This article is distributed under the terms of the Creative Commons Attribution License, which permits unrestricted use and redistribution provided that the original author and source are credited.

\section{Introduction}

$B$ cell development starts in the bone marrow where immature B cells must assemble and express on their surface a functional but non-self-reactive B cell antigen receptor (BCR) (Lefranc and Lefranc, 2001). The generation of the heavy and light chain of the BCR is mediated by the random and imprecise process of $\mathrm{V}(\mathrm{D}) \mathrm{J}$ recombination (Tonegawa, 1983). Further development of $\mathrm{B}$ cells occurs in the periphery in response to stimulation with the process of somatic hypermutation (SHM) through which point mutations are introduced in the genes coding for the $V(D) J$ part of the immunoglobulin heavy (IgH) and light chain (Jolly et alı, 1996). Subsequently, B cells with a mutated BCR providing increased antigen affinity are selected and show increased survival and proliferation capacity (Zheng et al., 2005).

Furthermore, class switch recombination (CSR) modifies the $\mathrm{IgH}$ constant region, resulting in the generation of $B$ cells with nine different immunoglobulin isotypes or isotype subclasses, namely $\operatorname{lgD}$, $\lg$ M, IgG1-4, IgA1/2 and lgE (Stavnezer et al., 2008). This process involves the replacement of the proximal heavy chain constant gene by a more distal gene. Class switching is an essential mechanism during humoral immune responses as the constant region of an antibody determines its effector function (Vidarsson et al., 2014). Both direct switching and sequential switching upon a second round of antigen exposure have been reported (Horns et al., 2016; Cameron et al., 2003; Zhang et al., 1994). 
Through developmental mechanisms and further differentiation in the periphery, several phenotypically distinct circulating B cell subpopulations are generated (Allman and Pillai, 2008). They include naïve, marginal zone (MZ), switched memory B cells and plasma cells (PC), which are mainly characterised by their differential expression of surface markers and by playing distinct roles in the adaptive immune response (Leandro, 2013 ) High-throughput sequencing of the lgH repertoire (AIRR-seq) has made it possible to improve our understanding of the different components of the adaptive immune system in health and disease, and following vaccine challenge (Mandric et al., 2020; Ghraichy et al., 2018; Galson et al., 2014; Lindau and Robins, 2017; Georgiou et al., 2014). Previous studies using both high- and low-throughput sequencing techniques have already reported important differences between $\mathrm{B}$ cell subpopulations affecting their $\mathrm{lgH}$ repertoire composition, VDJ gene usage, mutations and clonality (Berkowska et al., 2011; Mroczek et al., 2014; Galson et al., 2015; Wu et al., 2010).

Recent AIRR-seq workflows allow coverage of a sufficient part of the lgH constant region in addition to the VDJ region, making it possible to assign antibody classes and subclasses on an individual sequence level. It is common practice to use unsorted bulk B cells from peripheral blood as a starting material and use the constant region information combined with the degree of SHM to group transcripts in silico into different B cell populations (Glanville et al., 2011; Ghraichy et al., 2020). Using isotype-resolved IgH sequencing of bulk B cells, isotype subclasses have been found to show differences in their repertoire characteristics (Jackson et al., 2014; Kitaura et al., 2017). However, it remains unknown how the $\mathrm{lgH}$ repertoire of bioinformatically separated transcripts originating from bulk-sequenced B cells compares to the repertoire of their corresponding circulating B cell subpopulations. It is also unknown how $\mathrm{lgH}$ sequences with the same constant region originating from different cell types compare.

Here, we used an established AIRR-seq workflow that captures the diversity of the variable IgH genes together with the isotype subclass usage to study in detail the repertoire of CD19+ bulk B cells as well as flow cytometry sorted naïve, MZ, switched and PCs from 10 healthy adults. We applied statistical methods such as principal component analysis (PCA), k-means clustering, linear discriminant analysis (LDA) and machine learning algorithms to combine several repertoire metrics and characterise the different B cell subpopulations. We show that transcripts from physically sorted B cell subpopulations share similar characteristics with their corresponding subsets in the bulk that were grouped in silico using isotype subclass information and number of mutations. We further demonstrate that sequences with the same isotype subclass originating from different cell types are closely related, suggesting the presence of isotype-specific rather than cell-type-specific signatures in the $\operatorname{lgH}$ repertoire. We finally correlate these signatures to the isotype subclass positioning on the locus and find that downstream subclasses exhibit enhanced signs of maturity, overall providing new insights into the selection and the peripheral differentiation of distinct B cell subpopulations.

\section{Results}

\section{Physically sorted B cell subpopulations and their corresponding subsets in the bulk share similar repertoire characteristics}

We compared IgH repertoire characteristics between the following $B$ cell subpopulations: $B_{\text {naive, }} B_{M Z}$, $B_{P C \_M D}, B_{P C \_A G}$ and $B_{\text {switched }}$ and their corresponding subsets that we obtained in silico from $B_{\text {bulk: }}$ : $B_{\text {bulk_naive, }}$ $B_{\text {bulk_MD }}$ and $B_{\text {bulk_switched. }}$. We identified three separate clusters: one made of predominantly $B_{M Z}, B_{\text {bulk_MD }}$ and $\mathrm{B}_{\mathrm{PC} \_\mathrm{MD}}$; another with only $\mathrm{B}_{\text {naive }}$ and $\mathrm{B}_{\text {bulk_naive; }}$ and a third cluster with predominantly $\mathrm{B}_{\text {bulk_switched, }}, \mathrm{B}_{\mathrm{PC}}$ $A G$ and $B_{\text {switched }}$ (Figure $1 \mathrm{~A}$ ) by combining all repertoire characteristics in a PCA and applying k-means clustering. To test whether this clustering pattern was driven by VJ gene usage, complementaritydetermining region (CDR) 3 physiochemical properties or the general repertoire metrics, we analysed these variables separately. Using $V$ family and $J$ gene usage, there was a clear separation between naïve and memory cells mostly driven by differences in V1/3 and J4/6 usage (Figure 1-figure supplement 1). However, no separation between $B_{M Z} / B_{P C \_M D} / B_{\text {bulk_MD }}$ and $B_{\text {switched }} / B_{P C} A G / B_{\text {bulk_switched }}$ was observed (Figure 1B). The CDR3 physiochemical properties alone created similar clusters as when combined together with the other metrics (Figure 1C). This separation was mostly driven by a lower basic and a higher aromatic content in addition to a higher gravy index and a lower polarity in $B_{\text {naive }} / B_{\text {bulk_naive }}$ compared to memory subpopulations (Figure 1-figure supplement 2). Global repertoire metrics also created a clear separation between $B_{\text {naive }} / B_{\text {bulk_naive, }} B_{\text {switched }} / B_{P C_{\_} A G} / B_{\text {bulk_switched }}$ and $B_{M Z} / B_{P C \_M D} / B_{\text {bulk_MD }}$ 

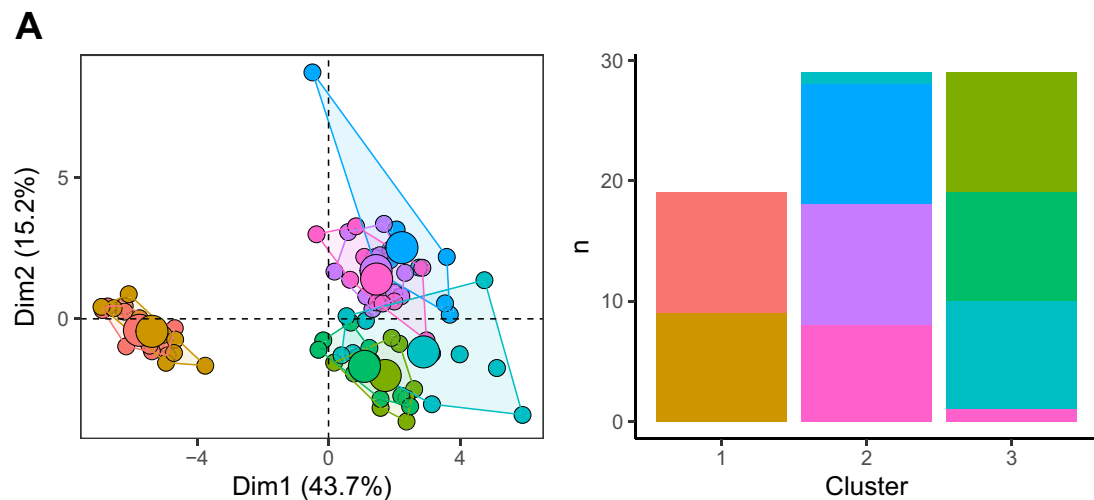

B
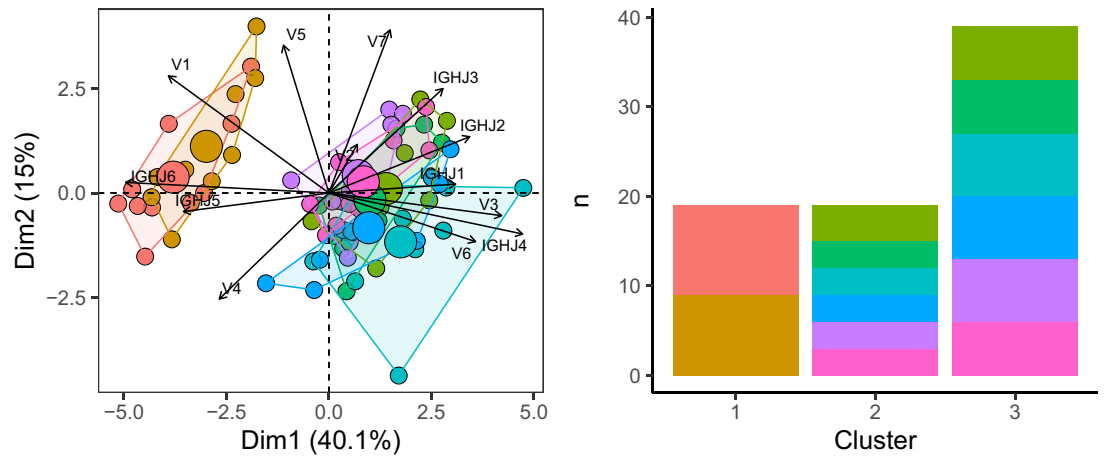

C
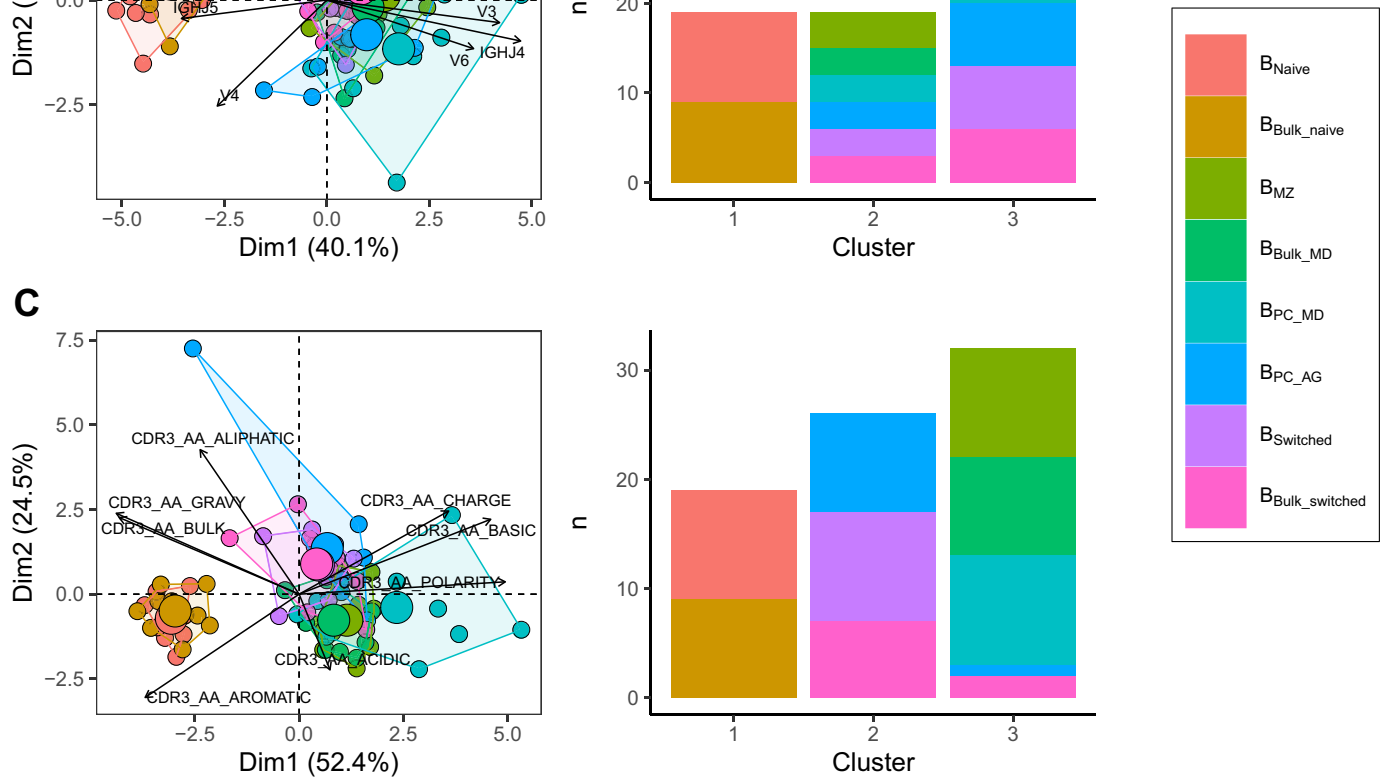

D
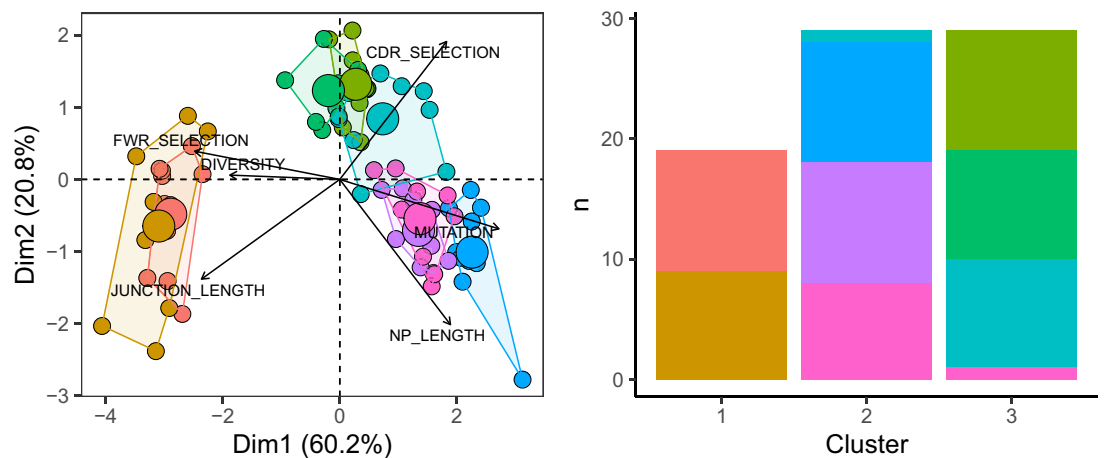

Figure 1. Different repertoire characteristics similarly separate between $B$ cells subpopulations. Principal component analysis (PCA) (left) and composition of the clusters formed using k-means clustering with $\mathrm{k}=3$ (right) applied on (A) all repertoire characteristics, (B) $\vee$ family and $\mathrm{J}$ gene usage (see Figure 1-figure supplement 1), (C) physiochemical properties of CDR3 junction (see Figure 1-figure supplement 2) and (D) global repertoire metrics (see Figure 1-figure supplement 3). The percentage of all variation in the data that is explained by PC1 and PC2 is shown on the $x$ and $y$ axis, Figure 1 continued on next page 
Figure 1 continued

respectively, between brackets. In the PCA plots, areas are the convex hulls of the subsets, and the largest point of one colour represents the centre of that hull.

The online version of this article includes the following figure supplement(s) for figure 1:

Source data 1. Related to Figure 1A-D.

Figure supplement 1. Differences in $V$ and $J$ gene usage across different $B$ cell subpopulations.

Figure supplement 2. Comparison of CDR3 amino acid physiochemical properties in different B cell subpopulations.

Figure supplement 3. Comparison of global repertoire metrics in different B cell subpopulations.

subpopulations mostly driven by higher mutation counts, NP length and selection pressure in the CDR and lower junction length and diversity in $B_{\text {switched }}$ compared to $B_{\text {naive }}$ (Figure 1-figure supplement 3 ).

In summary, we found that $V$ family and $J$ gene usage, the physiochemical properties of the CDR3 and global repertoire metrics similarly distinguish between $B$ cell subpopulations. $B_{\text {naive, }} B_{M Z} / B_{P C}{ }_{M D}$ and $\mathrm{B}_{\text {switched }} / \mathrm{B}_{\mathrm{PC} \_\mathrm{AG}}$ were divergent but shared properties with their relative corresponding subsets in the bulk.

\section{Accurate prediction of cell type based on repertoire features on a single-cell level}

We constructed a sequence classifier that predicts the cell type of a sequence using sequence attributes and different repertoire metrics. Since we subsampled our data making our datasets perfectly balanced, we used only accuracy as a performance metric. Logistic regression, decision tree and random forest classifiers all performed satisfactorily (Figure 2A). However, logistic regression performed poorly on correctly classifying $B_{\text {switched }}$ and $B_{P_{C} A G}$, for which accuracy was almost equal to chance. The performance of all three classifiers was highest in distinguishing between $B_{\text {naive }}$ and other cell types.

The random forest classifier was the most successful compared to the other two and the most accurate in predicting the cell type of a sequence. We assessed the relevance of specific predictors in properly classifying cell types by calculating feature importance scores for each cell pair (Figure 2B). The number of mutations was the highest scoring feature for all cell pairs except for distinguishing between $B_{\text {switched }}$ and $B_{P_{P} \_A G}$ and between $B_{M Z}$ and $B_{P_{P} \_M D}$ for which CDR3 amino acid characteristics had higher scores. Within the CDR3 physiochemical properties, average bulkiness, average polarity and the gravy hydrophobicity index were the most differentiating between cell types, whereas the basic and acidic content of the CDR3 chain seemed to be less important. R/S ratio in CDR and FWR and the junction length appeared to have similar scores and were more important in cases where $B_{\text {naive }}$ were not one of the two cell types. $V$ family and $J$ gene appeared to have low importance in distinguishing between all cell pairs.

\section{Within class-switched subsets, sequences with same constant region from different cell types show similar features}

When comparing class-switched transcripts originating from $B_{\text {bulkswitched }} B_{\text {switched }}$ and $B_{P C \_A G}$, isotype subclasses were similarly distributed. IgA1 was the dominant subclass in IgA transcripts, whereas IgA2 was less frequently used. All cell subpopulations showed a dominant use of lgG1 and lgG2 with little IgG3 and negligible IgG4 (Figure 3A). Usage of IgA1 in $B_{P C_{-A G}}$ was similar to $B_{\text {switched }}$ and $B_{\text {bulk_switched }}$ ( $p=0.28$ and $p=0.25$, Kruskal-Wallis). IgG3 usage was significantly lower in $B_{P C_{-} A G}$ compared to $B_{\text {bulk }}$ switched and $B_{\text {switched }}(p=0.01, p=0.01$, Kruskal-Wallis) while IgG1 usage tended to be lower $(p=0.13$ and $p=0.11$, Kruskal-Wallis) and IgG2 usage higher in $B_{P C_{-} A G}$ compared to the other two $B$ cell subpopulations ( $p=0.11$ and $p=0.11$, Kruskal-Wallis).

When combining repertoire characteristics by isotype subclass and cell type for class-switched transcripts resulting from $B_{\text {bulk_switched, }} B_{\text {switched }}$ and $B_{P C \_A G}$, we found that samples with the same constant region originating from different cell types overlapped (Figure $3 B$ ). We identified two clusters: one mainly composed of $\lg \mathrm{G} 1$ and $\lg G 3$ samples from all cell types and another with $\lg \mathrm{A} 1, \lg \mathrm{A} 2$ and lgG2 samples by applying k-means clustering with $\mathrm{k}=2$ (Figure 3C). By further dividing the data and with increasing $k$, we observed that newly formed clusters were mainly composed of distinct isotype 


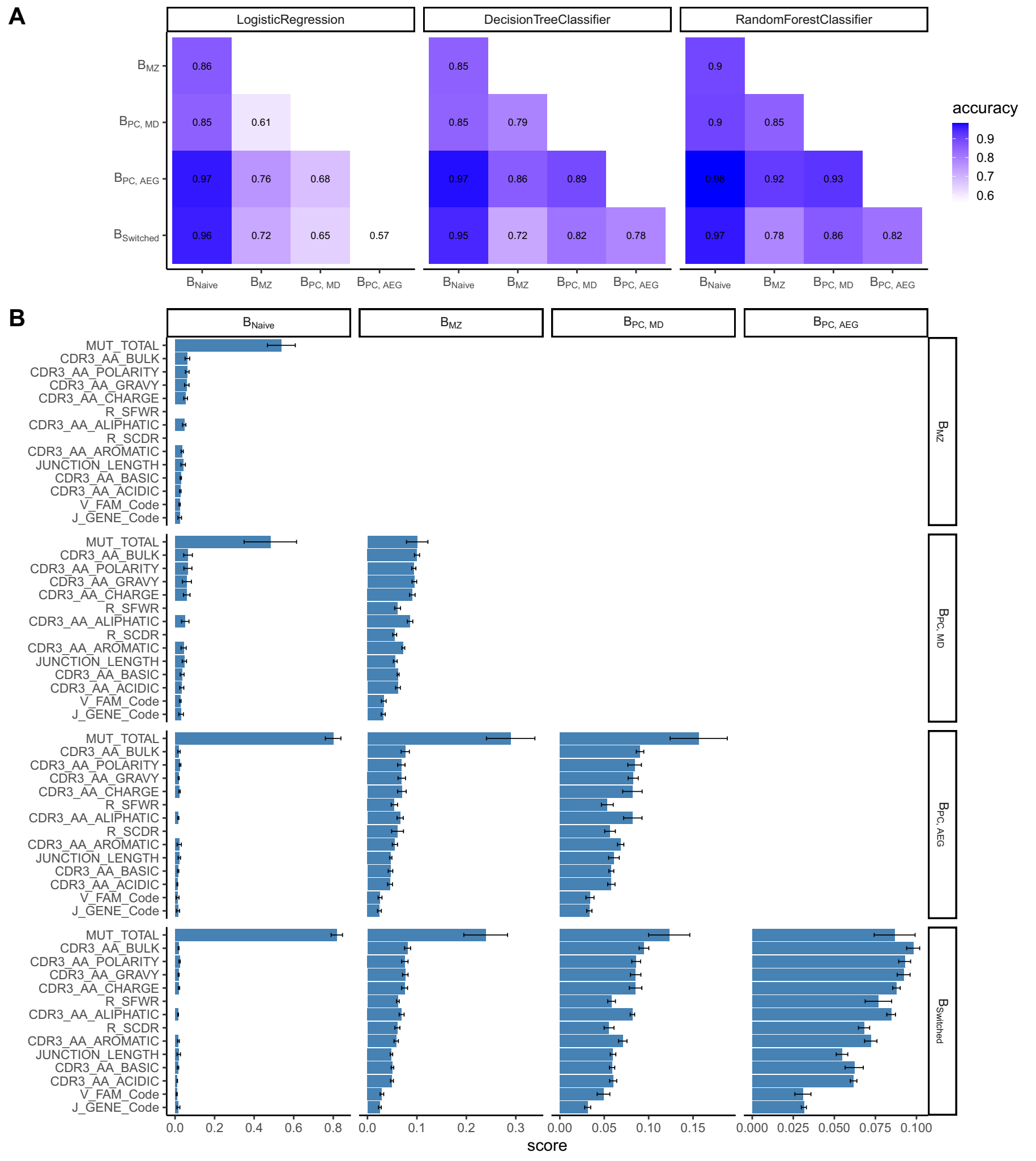

Figure 2. Classification accuracies and feature scores on a single-sequence level. (A) Heatmap showing pairwise classification accuracy results using logistic regression, decision tree and random forest classifier. (B) Random forest feature scores by cell pair. 


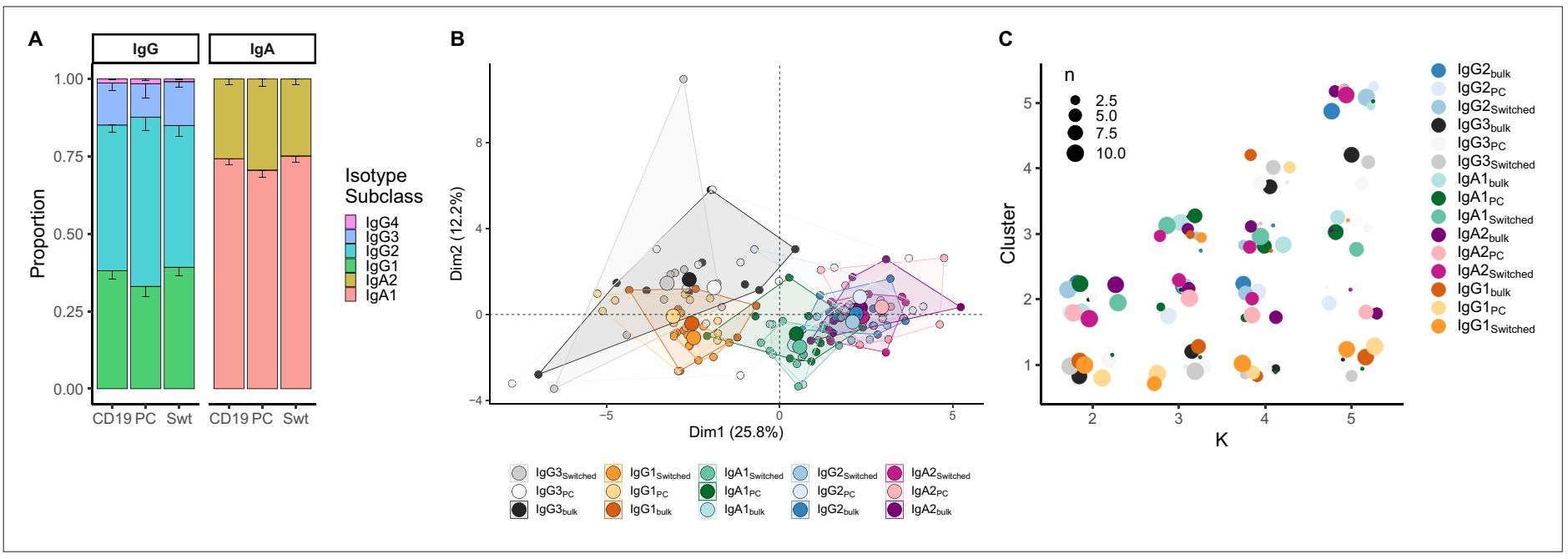

Figure 3. Analysis of isotype subclasses in IgG and IgA transcripts. (A) Isotype subclass distribution by cell type. Error bars represent the standard error of the mean. (B) Principal component analysis (PCA) on all repertoire properties combined by cell type and isotype subclass. Areas are the convex hulls of a group, and the largest point of one colour represents the centre of that hull. (C) Composition of the clusters formed by applying the k-means clustering algorithm on all data with increasing $\mathrm{k}$ from $\mathrm{k}=2$ to $\mathrm{k}=5$. Underlyaing source data can be found under Figure 4-source data 1.

subclasses, while the cell type itself was not a defining factor for cluster formation. Interestingly, we could not see a clear separation between $\lg G 2$ and $\lg A 2$ samples with increasing number of clusters.

\section{B cell repertoire metrics correlate with constant region positioning on the IgH locus in class-switched subsets}

The $\lg \mathrm{H}$ locus contains nine constant genes. The genes encoding for $\lg \mathrm{M}$ and $\lg \mathrm{D}$ are the closest to the V-D-J recombination sites while those for $\lg \mathrm{G} 3$, IgG1 and $\lg A 1$ are further downstream but still close to $\lg \mathrm{M} / \lg D$, whereas more distant on the locus are the genes that encode for $\lg G 2$, $\lg G 4$, $\lg E$ and IgA2 (Figure 4A). We determined and compared $B$ cell repertoire metrics between different subclasses in $B_{P C}$ and $B_{\text {switched }}$ and compared those to $B_{\text {naive }}$ and $B_{M Z}$. $B_{\text {naive }}$ showed the lowest number of mutations and R/S ratio and longest CDR3 junction. Memory subsets had a high number of mutations, with $\mathrm{B}_{\mathrm{MZ}}$ and $\mathrm{B}_{\mathrm{PC} \_\mathrm{MD}}$ having fewer mutations than class-switched transcripts (Figure 4B). IgM-distal subclasses $\lg G 2$ and IgA2 in both $B_{\text {switched }}$ and $B_{P C_{-A G}}$ showed the highest R/S ratio, indicating high selection pressure (Figure $4 C$ ). All antigen-experienced subsets had a lower junction length compared to $B_{\text {naive }}$ except for IgM-proximal transcripts $\lg G 3$ and IgG1 (Figure 4E). The proportion of IGHV4-34, the gene associated with self-reactivity (Bashford-Rogers et al., 2018), was lower in memory subsets compared to $B_{\text {naive }}$ except for IgG3 from $B_{\text {switched }}$ for which the proportion of IGHV4-34 was similar to naïve subsets (Figure 4F). Within IgG and IgA sequences, genomic distance from IgM correlated with a higher R/S ratio, shorter junction and lower usage of IGHV4-34. $B_{\mathrm{PC}}$ had a significantly lower diversity compared to all other cell types (Figure 4G). Interestingly, transcripts from $B_{\text {switched }}$ showed a similar diversity to $B_{\text {naive, }}$ whereas $B_{M Z}$ were less diverse. Within $B_{P_{C} \_A G}$ IgM-distal subclasses showed a lower diversity.

IGHV family and IGHJ gene usage also showed a discrepancy between different subsets. IGHV family usage in lgM-proximal subclasses $\lg G 3$ and $\lg G 1$ was similar to $B_{\text {Naive. }} B_{M z}$ and IgM-distal subclasses were enriched in IGHJ4 at the expense of IGHJ6 compared to naïve cells and IgG1-3 B cell subsets (Figure 4-figure supplement 1). To reduce the dimensionality of all data points into a single one-dimensional axis, we performed LDA fitted on the relative gene frequencies (Figure 4H). This showed a clear distinction between $B_{\text {naive, }} \lg G 1-3$ and $B_{\mathrm{Mz}}, \lg G 2$ and $\lg A 1-2$. An LDA fitted on the physiochemical properties of the CDR3 junction also showed a clear distinction between naïve and memory subsets, with $\lg G 3$ and $\lg G 1$ being closest to $\mathrm{B}_{\text {naive }}$ and $\lg \mathrm{G} 2$ and $\lg \mathrm{A} 2$ overlapping and furthest away (Figure 4I).

In summary, we found that in $\lg A$ and $\lg G$ subclasses different $B$ cell repertoire metrics correlate with the positioning of their respective subclass genes on the $\mathrm{IgH}$ locus, namely with the increasing genomic distance from IgM, with the proximal-switched IgH subclasses being more similar to naïve. 


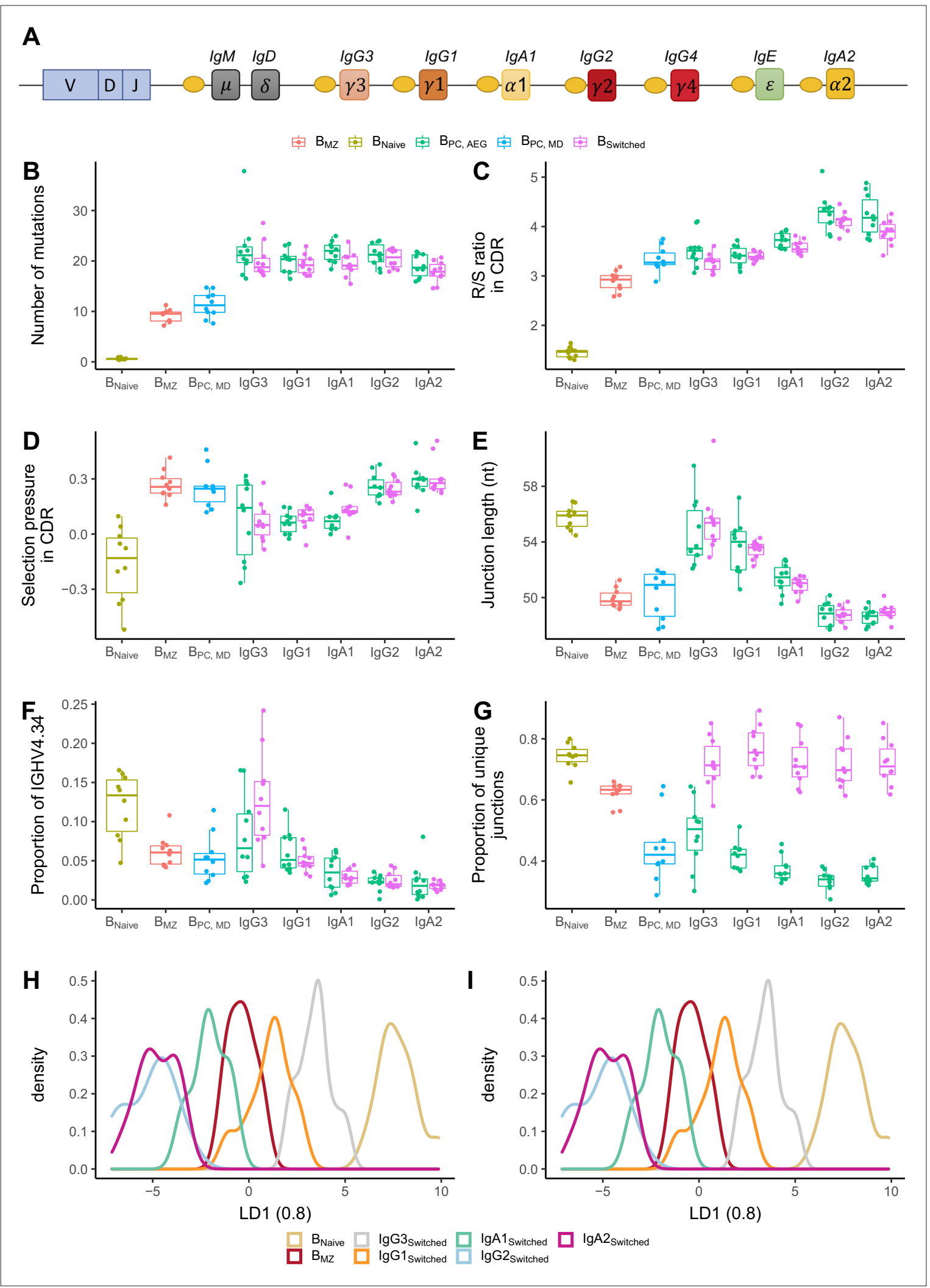

Figure 4. Analysis of repertoire metrics by isotype subclass and cell type. (A) Overview of the lgH constant region locus. Comparison of (B) mutation counts, (C) R/S ratio, (D) selection pressure, (E) junction length, (F) proportion of IGHV4-34 and (G) diversity between different B cell subpopulations. Linear discriminant analysis (LDA) fitted on (H) V family and J gene usage (see Figure 4-figure supplement 1) and (I) CDR3 amino acid physiochemical properties.

Figure 4 continued on next page 
Figure 4 continued

The online version of this article includes the following figure supplement(s) for figure 4:

Source data 1. Related to Figure 3 and Figure 4.

Figure supplement 1. Differences in $\mathrm{V}$ and $\mathrm{J}$ usage across different $\mathrm{B}$ cell subpopulations and istotype subclasses.

Memory lgM subsets ( $B_{M z}$ and $B_{P C \_M D}$ ) were found to have lower mutations and $R / S$ ratio than classswitched subsets. However, in other properties such as junction length, proportion of IGHV4-34 and diversity, they were more similar to IgM-distal subclasses.

\section{Discussion}

Here, we used AIRR-seq to characterise similarities and differences in the $\mathrm{lgH}$ repertoire of bulk B cells and different sorted naïve and memory B cell populations. This allowed for an in-depth understanding of the mechanisms underlying $B$ cell responses. We report differences in $V$ family and $J$ gene usage, CDR3 physiochemical properties and global repertoire characteristics that similarly distinguish between naïve, IgM/lgD memory and class-switched subsets both the repertoire and at the sequence level. Furthermore, we show alterations in the repertoire characteristics at the isotype subclass level unrelated to cell type that correlate with the position of the constant gene on the $\operatorname{lgH}$ locus. This study provides powerful insight on biological mechanisms underlying the B cell response as well as novel understanding of AIRR-seq methodologies to be taken into account in future studies.

Earlier studies have revealed differences in gene usage and repertoire properties between different sorted B cell subpopulations (Mroczek et al., 2014; Wu et al., 2010; Briney et al., 2012a; Larimore et al., 2012; DeWitt et al., 2016; Bautista et al., 2020). In addition, some differences in repertoire characteristics across isotype subclasses have been determined by using bulk B cells as starting material (Jackson et al., 2014; Kitaura et al., 2017; de Jong et al., 2017). However, studies combining lgH sequencing from both bulk and sorted B cell subpopulations have been sparse. Here, we sought to compare $\mathrm{lgH}$ repertoire properties between transcripts sorted in silico from bulk B cells and physically sorted B cell subpopulations. In addition, using isotype-resolved sequencing, we aimed to perform a comparative analysis of the $\mathrm{lg} \mathrm{H}$ repertoire of transcripts with the same constant region originating from different cell types and correlate the differences in repertoire with position on the lgH locus. The type of material obtained, the sequencing depth and the experimental and computational methods used here constitute by far the most thorough and comprehensive analysis of repertoire differences between $B$ cell subsets and isotype subclasses and thereby provide unique insights into the underlying mechanisms, leading to the formation of different B cell subpopulations.

Previous work involving human naïve and antigen-experienced B cell repertoires havs shown naïve $B$ cells to have shorter junctions and higher usage of IGHJ6 and IGHV3, and lower usage of IGHJ4 and IGHV1 compared with IgM memory and switched B cells (Briney et al., 2012a; Larimore et al., 2012; DeWitt et al., 2016; Bautista et al., 2020). Differences in gene usage and CDR3 properties between IgM memory and switched B cells have also been reported (Wu et al., 2010). IgM memory and switched B cells have been found to use more negatively charged residues and to have less hydrophobic junctions compared with naïve B cells (Mroczek et al., 2014; Wu et al., 2010). Here, we focused on a more detailed examination of the repertoires by combining multiple characteristics using dimensionality reduction methods. Results of a previous study revealed that combining only a few repertoire characteristics is sufficient to discriminate between B cell subpopulations (Galson et al., 2015). In addition, an LDA combining $V$ gene family proportions has been found to successfully distinguish between IgM and IgG repertoires (Friedensohn et al., 2018). We extend these findings by showing that using $V$ family and J gene usage, CDR3 physiochemical properties or global repertoire characteristics similarly allow to separate between naïve and memory subpopulations. This suggests that distinct B cell subpopulations derive from different developmental mechanisms and are subject to selective processes that lead to similar variable gene identity. The importance of the CDR3 and its location at the centre of the antigen-binding site makes the observed differences in physiochemical properties and junction length interesting. These findings may suggest that different B cells subpopulations stimulated by diverse antigens have distinct junction compositions and properties. Further work to investigate CDR3-specific residue content and prediction of CDR3 protein structures could be enriching for antibody specificity and antigen recognition in different B cell subpopulations. 
Previous research has demonstrated that same B cell subpopulations from different donors are more similar in their repertoire characteristics than different B cell subpopulations within an individual (Briney et al., 2012b; Rubelt et al., 2016). This has led to the understanding that differences between naïve and memory cells are conserved across unrelated individuals. Our findings are in agreement with these observations, and we extend on those by showing that the main defining factor in repertoire similarity is the constant region type, namely the isotype subclass, and that differences between subclasses are conserved across both cell type and individual. This finding suggests the existence of an isotype-based mechanism for repertoire control that is constant across cell types and individuals.

In addition to the comparative analysis of the different peripheral B cell subsets, our study represents, to our knowledge, the first comparison of bulk B cell sequencing with sorted B cell subpopulations. We showed that sequencing unsorted B cells from peripheral blood and combining the constant region information with the degree of SHM to bioinformatically group transcripts yields accurate results comparable to physical sorting, especially when analysing global repertoire characteristics. We acknowledge that this might be limiting in tasks sensitive to potential biases from different RNA levels per cell such as identifying antigen-specific sequences from PCs.

Recent IgH repertoire studies have moved towards using machine learning and artificial intelligence in contrast to traditional statistical approaches for goals including vaccine design, immunodiagnostics and antibody discovery (Greiff et al., 2017; Ostmeyer et al., 2017; Konishi et al., 2019; Shemesh et al., 2021). Previous work has focused on representing repertoires as sequence or subsequencebased features, that is, overlapping amino acid k-mers and their Atchley biophysiochemical properties (Greiff et al., 2017; Ostmeyer et al., 2017). Here, we report a simple pairwise classifier that successfully predicts the cell type of a sequence based on only the commonly used sequence attributes such as number of mutations and junction length. Random forest and decision tree classifiers outperformed the logistic regression algorithm suggesting a non-linear separation between cell types. A common concern when applying machine learning is the possibility of over-fitting. To prevent this, we trained the algorithm on $80 \%$ of the data and tested its performance on the remaining unseen $20 \%$. We also subsampled every pair of classes to equal number of sequences in order to balance the dataset. The model presented here is applied only within an individual and is thereby confined by repertoire signals that might be individual-specific. More work improving the generalisability of the model across individuals would be revolutionising in terms of its potential practical applications. Unsurprisingly, the number of mutations was the most important feature in distinguishing between most cell types. These results, along with previous work, are promising and suggest that increasing the predictive potential of machine learning methods could help in finding sequence characteristics that distinguish between groups, such as disease state and healthy.

Studies indicate that both direct and sequential CSR to lgM-distal isotype subclasses can occur (Wesemann et al., 2011; Looney et al., 2016). Several studies have provided evidence for sequential CSR. IgM was found to commonly switch to proximal subclasses (lgG1, IgA1 and lgG2), but direct switches from IgM to more downstream subclasses (lgG4, lgE or lgA2) were rare (Horns et al., 2016). It has also been reported that a deficiency in lgG3, the most lgM-proximal subclass, frequently results in a decrease in other IgG subclasses (Meyts et al., 2006). Although it is challenging to determine whether sequential CSR occurs during a primary response, by re-entry into the germinal centre or during a secondary response to the same antigen, we and others have shown that IgM-distal subclasses accumulate with age, likely due to secondary encounter with antigen (Ghraichy et al., 2020; IJspeert et al., 2016). Studies comparing the mean mutation number between isotype subclasses have shown contradicting results. In one study, mutations varied in relation to the constant region position on the lgH locus, with the closest to lgM (lgG3) having the lowest mutations (Jackson et al., 2014), while in another study, no such difference was observed (Kitaura et al., 2017). We did not find a difference in number of mutations among lgG subclasses. Our findings rather suggest that mutation is more efficient in more downstream subclasses as we found that these exhibit higher R/S ratios and selection pressure in the CDR, consistent with previous studies (de Jong et al., 2017). Generally, class-switched IgM-distal subclasses showed signs of maturity (shorter junctions, lower IGHV4-34 usage) while transcripts from class-switched IgM proximal subclasses were more similar to those of naïve B cells. These results suggest that sequential CSR subjects $B$ cells to selective forces, leading to more mature variable gene properties without necessarily accumulating more mutations. 
In summary, in this study we took an extensive look at the $\mathrm{lg} \mathrm{H}$ repertoire of different flow cytometry sorted as well as bioinformatically grouped cell types and isotype subclasses of healthy individuals. Using advanced bioinformatic tools, statistical analysis and machine learning, this analysis provides deep insight into the different mechanisms of B cell development and boosts our understanding of the $\mathrm{B}$ cell system components in health. The data and methods presented here provide a foundation for future work investigating the immune repertoire of patients with altered immune status and hold promise for the application of AIRR-seq along with machine learning techniques in clinical and diagnostic settings.

Key resources table

\section{Materials and methods}

\begin{tabular}{|c|c|c|c|c|}
\hline $\begin{array}{l}\text { Reagent type (species) or } \\
\text { resource }\end{array}$ & Designation & $\begin{array}{l}\text { Source or } \\
\text { reference }\end{array}$ & Identifiers & $\begin{array}{l}\text { Additional } \\
\text { information }\end{array}$ \\
\hline Antibody & Anti-human CD19-PE (mouse monoclonal) & BioLegend & $\begin{array}{l}\text { Cat\# 363003; } \\
\text { RRID:AB_2564125 }\end{array}$ & FACS $(5 \mu$ l per test) \\
\hline Antibody & $\begin{array}{l}\text { Anti-human CD27-FITC (mouse } \\
\text { monoclonal) }\end{array}$ & BioLegend & $\begin{array}{l}\text { Cat\# 302806; } \\
\text { RRID:AB_314298 }\end{array}$ & FACS (5 $\mu$ l per test) \\
\hline Antibody & $\begin{array}{l}\text { Anti-human CD38-APC/Fire } 750 \text { (mouse } \\
\text { monoclonal) }\end{array}$ & BioLegend & $\begin{array}{l}\text { Cat\# 356626; } \\
\text { RRID:AB_2616713 }\end{array}$ & FACS $(5 \mu$ l per test) \\
\hline Antibody & Anti-human IgD-APC (mouse monoclonal) & BioLegend & $\begin{array}{l}\text { Cat\# 348222; } \\
\text { RRID:AB_2561595 }\end{array}$ & FACS $(5 \mu$ l per test) \\
\hline Antibody & $\begin{array}{l}\text { Anti-human IgM-Pacific Blue (mouse } \\
\text { monoclonal) }\end{array}$ & BioLegend & $\begin{array}{l}\text { Cat\# 314513; } \\
\text { RRID:AB_10574306 }\end{array}$ & FACS $(5 \mu$ l per test) \\
\hline
\end{tabular}

\section{Sample collection and cell sorting}

This was a descriptive study, hence no formal sample size calculation was performed. Buffy coat samples were obtained from 10 anonymous healthy adults, hence no approval from the local ethics committee was necessary. B cells were first isolated by magnetic cell sorting using the human CD19 MicroBeads (Miltenyi Biotec, San Diego, CA) and the AutoMACS magnetic cell separator. From 9 out of the 10 samples, $3 \times 10^{6}$ bulk $C D 19^{+} \mathrm{B}$ cells $\left(B_{\text {bulk }}\right)$ were lysed and stored at $-80^{\circ} \mathrm{C}$. The remaining cells were sorted by flow cytometry into four subpopulations using cell surface markers characteristic for naïve ( $\left.B_{\text {naive }}\right), M Z\left(B_{M Z}\right), P C s\left(B_{P C}\right)$ and switched memory $B$ cells $\left(B_{\text {switched }}\right)$. Cells were then lysed and stored at $-80^{\circ} \mathrm{C}$. Surface markers, demographics, number of cells and purity of each sample are outlined in Supplementary file 1.

\section{RNA extraction and library preparation}

RNA extraction was performed on the lysate using the RNeasy Mini Kit (Qiagen, Hilden, Germany). Libraries were prepared as previously described (Ghraichy et al., 2020). Briefly, two reverse transcription (RT) reactions were carried out for each RNA sample resulting from $B_{\text {bulk }}$ or $B_{\mathrm{PC}}$ : one with equal concentrations of $\lg \mathrm{M}$ and $\lg \mathrm{D}$-specific primers and another with $\lg \mathrm{A}, \lg \mathrm{G}$ and $\lg \mathrm{E}$-specific primers. Only one RT reaction with IgM and IgD-specific primers was performed on $B_{\text {naive }}$ and $B_{M z}$ samples; similarly, we applied one $R T$ reaction with $\lg A$, lg $G$ and $\lg E$ primers on samples obtained from $B_{\text {switched. }}$. IgH cDNA rearrangements were then amplified in a two-round multiplex PCR using a mix of IGHV region forward primers and Illumina adapter primers, followed by gel extraction for purification and size selection. The final concentration of PCR products was measured using Qubit prior to library preparation and combined with a total of 12 equally concentrated samples. Final libraries barcoded with individual i7 and i5 adapters were sequenced in each run on the Illumina MiSeq platform $(2 \times$ 300 bp protocol).

\section{Data preprocessing}

Preprocessing of raw sequences was carried out using the Immcantation toolkit and as per Ghraichy et al., 2020; Vander Heiden et al., 2014; Gupta et al., 2015. Briefly, samples were demultiplexed based on their Illumina tags. A quality filter was applied, paired reads were joined and then collapsed according to their unique molecular identifier (UMI). Identical reads with different UMI were further 
collapsed, resulting in a dataset of unique sequences. VDJ gene assignment was carried out using IgBlast (Ye et al., 2013). Isotype subclass annotation was carried out by mapping constant regions to germline sequences using stampy (Lunter and Goodson, 2011). The number and type of $V$ gene mutations was determined as the number of mismatches with the germline sequence using the $R$ package shazam (Gupta et al., 2015). The R package alakazam was also used to calculate the physicochemical properties of the CDR3 amino acid sequences (Gupta et al., 2015). Selection pressure was calculated using BASELINe and the statistical framework used to test for selection was CDR_R/ (CDR_R + CDR_S) (Yaari et al., 2012).

\section{In silico grouping of sequences}

For $B_{\text {bulk }}$ samples, we used the constant region information combined with the mutation counts to classify individual sequences into different subsets. IgD and $\lg M$ sequences with up to 2 nt mutations across the entire $V$ gene were considered 'unmutated' ( $B_{\text {bulk_naive }}$ ) to account for remaining PCR and sequencing bias. The remaining mutated $\lg D$ and $\lg M$ sequences were labelled as $\operatorname{lgD} / \lg M$ memory $\left(B_{\text {bulk_MD }}\right)$. All class-switched sequences were defined as antigen-experienced regardless of their $V$ gene mutation count $\left(B_{\text {bulk_switched }}\right)$. We split the sequences originating from $B_{P C}$ into two categories: lgM/ $\operatorname{lgD} B_{P C}\left(B_{P C}{ }_{M D}\right)$ and switched IgG/lgA PCs $\left(B_{P C} A G\right)$ according to the constant region of the sequences.

\section{Summarising repertoire characteristics}

$\checkmark$ family and $\mathrm{J}$ gene usage was calculated in proportions for each individual and cell type. We summarised the mean of the following CDR3 physiochemical characteristics: hydrophobicity, bulkiness, polarity, normalised aliphatic index, normalised net charge, acidic side chain residue content, basic side chain residue content, aromatic side chain content by individual and cell type.

Mean junction length, number of mutations and numbers of non-template $(N)$ and palindromic $(P)$ nucleotide added at the junction were calculated by individual and cell type. Selection pressure was summarised separately in CDR and framework region (FWR). Diversity was calculated as the proportion of unique junctions out of total transcripts. The preceding characteristics are referred to as global repertoire metrics.

\section{Dimensionality reduction and clustering}

PCA and k-means clustering were applied to the different repertoire characteristics to explore and find associations in the data. They were applied using the internal $\mathrm{R}$ functions prcomp() and $\mathrm{kmeans}()$ ( $R$ Development Core Team, 2018). LDA was performed using the R function Ida() from the package MASS (Venables and Ripley, 2002).

\section{Sequence classifier}

We constructed the sequence classifier using the sklearn package in Python (Pedregosa, 2015). Because we have the constant region information and to avoid error accumulation, we performed a pairwise classification, thereby transforming the multiclass problem into a binary classification. Within every participant and for every pair of cells, we subsampled to the lower sequence number to avoid bias and dataset imbalance. We used the number of mutations, the physiochemical properties and the junction length as numerical input features. The $\mathrm{V}$ gene family and $\mathrm{J}$ gene were one-hot encoded. In the case where the naïve cells were not one of the two classes, the replacement/silent (R/S) mutation ratios in CDR and FWR were included as features. We split the data into training and testing set using the default test size of 0.2. We used logistic regression, decision tree and random forest classifiers for prediction. The accuracy was recorded to judge the overall performance of the models. For every pair of classes, the mean accuracy of the 10 samples was calculated.

\section{Acknowledgements}

This work was supported by Swiss National Science Foundation (Ambizione-SCORE. PZ00P3_161147 and PZOOP3_183777) (JT); Gottfried und Julia Bangerter-Rhyner-Stiftung (JT); Olga Mayenfisch Stiftung (JT); Palatin-Stiftung (JT); Investment fund of the University of Zurich (JT). Biotechnology and Biological Sciences Research Council (BBSRC) (AK); UCB Pharma Ltd (AK); Royal Comission for the Exhibtion of 1851 Industrial Fellowship (AK). 


\section{Additional information}

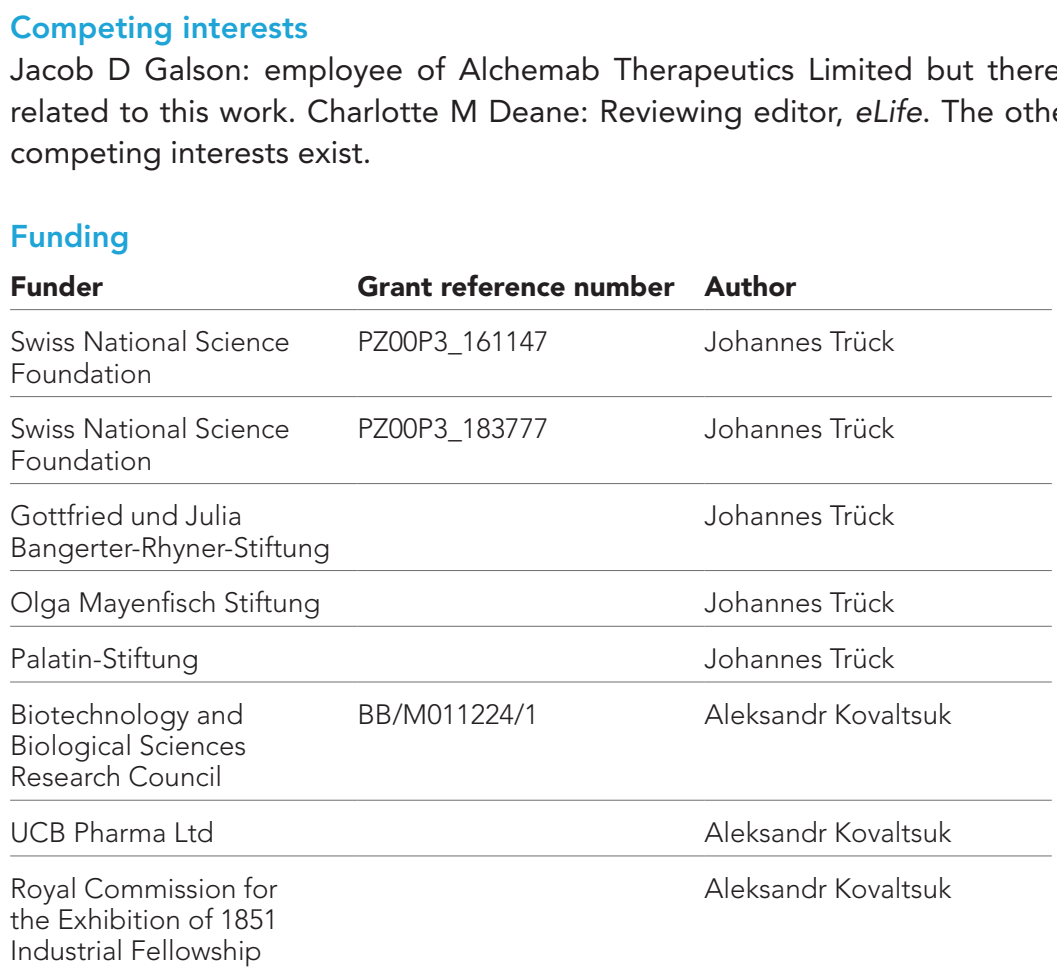

The funders had no role in study design, data collection and interpretation, or the decision to submit the work for publication.

Author contributions

Marie Ghraichy, Data curation, Formal analysis, Investigation, Methodology, Resources, Software, Visualization, Writing - original draft, Writing - review and editing; Valentin von Niederhäusern, Data curation, Formal analysis, Methodology, Resources, Writing - review and editing; Aleksandr Kovaltsuk, Conceptualization, Funding acquisition, Methodology, Writing - review and editing; Jacob D Galson, Methodology, Software, Writing - review and editing; Charlotte M Deane, Funding acquisition, Supervision, Writing - review and editing; Johannes Trück, Conceptualization, Funding acquisition, Methodology, Project administration, Supervision, Writing - original draft, Writing - review and editing

\section{Author ORCIDs}

Marie Ghraichy (DiD) http://orcid.org/0000-0002-7348-796X

Jacob D Galson (iD http://orcid.org/0000-0003-4916-800X

Charlotte M Deane (iD http://orcid.org/0000-0003-1388-2252

Johannes Trück (iD http://orcid.org/0000-0002-0418-7381

Ethics

Human subjects: Buffy coat samples were obtained from 10 anonymous healthy adults, hence no approval from the local ethics committee was necessary.

Decision letter and Author response

Decision letter https://doi.org/10.7554/73111.sa1

Author response https://doi.org/10.7554/73111.sa2

\section{Additional files}

Supplementary files

- Supplementary file 1. Demographics, number of cells and purity of samples.

- Transparent reporting form 
Data availability

Raw data used in this study are available at the NCBI Sequencing Read Archive (https://www.ncbi.nlm. nih.gov/sra) under BioProject number PRJNA748239 including metadata meeting MiAIRR standards (32). The processed dataset is available in Zenodo (https://doi.org/10.5281/zenodo.3585046) along with the protocol describing the exact processing steps with the software tools and version numbers.

The following dataset was generated:

\begin{tabular}{lllll}
\hline Author(s) & Year & Dataset title & Dataset URL & Database and Identifier \\
\hline Ghraichy M, Trück J & 2021 & $\begin{array}{l}\text { lgH repertoire sequencing } \\
\text { in human B cell } \\
\text { subpopulations }\end{array}$ & $\begin{array}{l}\text { https://www.ncbi.nlm. NCBI BioProject, } \\
\text { nih.gov/bioproject/ } \\
\text { PRJNA748239/ }\end{array}$ & PRJNA748239 \\
\hline Ghraichy M, Trück J 2019 & $\begin{array}{l}\text { Pre-processed B cell } \\
\text { receptor repertoire } \\
\text { sequencing data from } \\
\text { BioProject PRJNA527941 }\end{array}$ & $\begin{array}{l}\text { https://doi.org/10. } \\
5281 / \text { zenodo.3585046 zenodo. 10.5281/ }\end{array}$ & Zenodo.35856 \\
& & & \\
\hline
\end{tabular}

\section{References}

Allman D, Pillai S. 2008. Peripheral B cell subsets. Current Opinion in Immunology 20: 14. DOI: https://doi.org/ 10.1016/j.coi.2008.03.014, PMID: 18434123

Bashford-Rogers RJM, Smith KGC, Thomas DC. 2018. Antibody repertoire analysis in polygenic autoimmune diseases. Immunology 155: 3-17. DOI: https://doi.org/10.1111/imm.12927, PMID: 29574826

Bautista D, Vásquez C, Ayala-Ramírez P, Téllez-Sosa J, Godoy-Lozano E, Martínez-Barnetche J, Franco M, Angel J. 2020. Differential Expression of IgM and IgD Discriminates Two Subpopulations of Human Circulating IgM+lgD+CD27+ B Cells That Differ Phenotypically, Functionally, and Genetically. Frontiers in Immunology 11: 736. DOI: https://doi.org/10.3389/fimmu.2020.00736, PMID: 32435242

Berkowska MA, Driessen GJA, Bikos V, Grosserichter-Wagener C, Stamatopoulos K, Cerutti A, He B, Biermann K, Lange JF, van der Burg M, van Dongen JJM, van Zelm MC. 2011. Human memory B cells originate from three distinct germinal center-dependent and -independent maturation pathways. Blood 118: 2150-2158. DOI: https://doi.org/10.1182/blood-2011-04-345579, PMID: 21690558

Briney BS, Willis JR, Hicar MD, Thomas JW, Crowe JE. 2012a. Frequency and genetic characterization of V(DD)J recombinants in the human peripheral blood antibody repertoire. Immunology 137: 56-64. DOI: https://doi. org/10.1111/j.1365-2567.2012.03605.x, PMID: 22612413

Briney BS, Willis JR, McKinney BA, Crowe JE. 2012b. High-throughput antibody sequencing reveals genetic evidence of global regulation of the naïve and memory repertoires that extends across individuals. Genes \& Immunity 13: 469-473. DOl: https://doi.org/10.1038/gene.2012.20

Cameron L, Gounni AS, Frenkiel S, Lavigne F, Vercelli D, Hamid Q. 2003. S epsilon S mu and S epsilon S gamma switch circles in human nasal mucosa following ex vivo allergen challenge: evidence for direct as well as sequential class switch recombination. Journal of Immunology 171: 3816. DOI: https://doi.org/10.4049/ jimmunol.171.7.3816, PMID: 14500683

de Jong BG, IJspeert H, Marques L, van der Burg M, van Dongen JJ, Loos BG, van Zelm MC. 2017. Human IgG2- and lgG4-expressing memory B cells display enhanced molecular and phenotypic signs of maturity and accumulate with age. Immunology and Cell Biology 95: 744-752. DOl: https://doi.org/10.1038/icb.2017.43, PMID: 28546550

DeWitt WS, Lindau P, Snyder TM, Sherwood AM, Vignali M, Carlson CS, Greenberg PD, Duerkopp N, Emerson RO, Robins HS. 2016. A public database of memory and naive B-cell receptor sequences. PLOS ONE 11: e0160853. DOl: https://doi.org/10.1371/journal.pone.0160853, PMID: 27513338

Friedensohn S, Lindner JM, Cornacchione V, lazeolla M, Miho E, Zingg A, Meng S, Traggiai E, Reddy ST. 2018. Synthetic standards combined with error and bias correction improve the accuracy and quantitative resolution of antibody repertoire sequencing in human naïve and memory B cells. Frontiers in Immunology 9: 1401. DOI: https://doi.org/10.3389/fimmu.2018.01401, PMID: 29973938

Galson JD, Pollard AJ, Trück J, Kelly DF. 2014. Studying the antibody repertoire after vaccination: practical applications. Trends in Immunology 35: 5. DOl: https://doi.org/10.1016/j.it.2014.04.005, PMID: 24856924

Galson JD, Clutterbuck EA, Trück J, Ramasamy MN, Münz M, Fowler A, Cerundolo V, Pollard AJ, Lunter G, Kelly DF. 2015. BCR repertoire sequencing: different patterns of B-cell activation after two Meningococcal vaccines. Immunology and Cell Biology 93: 885-895. DOl: https://doi.org/10.1038/icb.2015.57, PMID: 25976772

Georgiou G, Ippolito GC, Beausang J, Busse CE, Wardemann H, Quake SR. 2014. The promise and challenge of high-throughput sequencing of the antibody repertoire. Nature Biotechnology 32: 158-168. DOl: https://doi. org/10.1038/nbt.2782, PMID: 24441474

Ghraichy M, Galson JD, Kelly DF, Trück J. 2018. B-cell receptor repertoire sequencing in patients with primary immunodeficiency: a review. Immunology 153: 145-160. DOl: https://doi.org/10.1111/imm.12865, PMID: 29140551 
Ghraichy M, Galson JD, Kovaltsuk A, von Niederhäusern V, Pachlopnik Schmid J, Recher M, Jauch AJ, Miho E, Kelly DF, Deane CM, Trück J. 2020. Maturation of the Human Immunoglobulin Heavy Chain Repertoire With Age. Frontiers in Immunology 11: 1734. DOI: https://doi.org/10.3389/fimmu.2020.01734, PMID: 32849618

Glanville J, Kuo TC, von Büdingen HC, Guey L, Berka J, Sundar PD, Huerta G, Mehta GR, Oksenberg JR, Hauser SL, Cox DR, Rajpal A, Pons J. 2011. Naive antibody gene-segment frequencies are heritable and unaltered by chronic lymphocyte ablation. PNAS 108: 20066-20071. DOI: https://doi.org/10.1073/pnas. 1107498108, PMID: 22123975

Greiff V, Weber CR, Palme J, Bodenhofer U, Miho E, Menzel U, Reddy ST. 2017. Learning the High-Dimensional Immunogenomic Features That Predict Public and Private Antibody Repertoires. Journal of Immunology 199: 2985-2997. DOI: https://doi.org/10.4049/jimmunol.1700594, PMID: 28924003

Gupta NT, Vander Heiden JA, Uduman M, Gadala-Maria D, Yaari G, Kleinstein SH. 2015. Change-O: a toolkit for analyzing large-scale B cell immunoglobulin repertoire sequencing data. Bioinformatics 31: 3356-3358. DOI: https://doi.org/10.1093/bioinformatics/btv359, PMID: 26069265

Horns F, Vollmers C, Croote D, Mackey SF, Swan GE, Dekker CL, Davis MM, Quake SR. 2016. Lineage tracing of human B cells reveals the in vivo landscape of human antibody class switching. eLife: e16578. DOI: https://doi. org/10.7554/eLife.16578, PMID: 27828776

IJspeert H, van Schouwenburg PA, van Zessen D, Pico-Knijnenburg I, Driessen GJ, Stubbs AP, van der Burg M. 2016. Evaluation of the Antigen-Experienced B-Cell Receptor Repertoire in Healthy Children and Adults. Frontiers in Immunology 7: 410. DOI: https://doi.org/10.3389/fimmu.2016.00410, PMID: 27799928

Jackson KJL, Wang Y, Collins AM. 2014. Human immunoglobulin classes and subclasses show variability in VDJ gene mutation levels. Immunology \& Cell Biology 92: 729-733. DOI: https://doi.org/10.1038/icb.2014.44

Jolly CJ, Wagner SD, Rada C, Klix N, Milstein C, Neuberger MS. 1996. The targeting of somatic hypermutation. Seminars in Immunology 8: 159-168. DOI: https://doi.org/10.1006/smim.1996.0020

Kitaura K, Yamashita H, Ayabe H, Shini T, Matsutani T, Suzuki R. 2017. Different somatic hypermutation levels among antibody subclasses disclosed by a new next-generation sequencing-based antibody repertoire analysis. Frontiers in Immunology 8: 389. DOI: https://doi.org/10.3389/fimmu.2017.00389, PMID: 28515723

Konishi H, Komura D, Katoh H, Atsumi S, Koda H, Yamamoto A, Seto Y, Fukayama M, Yamaguchi R, Imoto S, Ishikawa S. 2019. Capturing the differences between humoral immunity in the normal and tumor environments from repertoire-seq of B-cell receptors using supervised machine learning. BMC Bioinformatics 20: 267. DOI: https://doi.org/10.1186/s12859-019-2853-y, PMID: 31138102

Larimore K, McCormick MW, Robins HS, Greenberg PD. 2012. Shaping of Human Germline IgH Repertoires Revealed by Deep Sequencing. Journal of Immunology 189: 3221-3230. DOI: https://doi.org/10.4049/ jimmunol.1201303, PMID: 22865917

Leandro MJ. 2013. B-cell subpopulations in humans and their differential susceptibility to depletion with anti-CD20 monoclonal antibodies. Arthritis Research \& Therapy 15 Suppl 1: S3. DOI: https://doi.org/10.1186/ ar3908, PMID: 23566754

Lefranc MP, Lefranc G. 2001. The Immunoglobulin Factsbook. Academic Press.

Lindau P, Robins HS. 2017. Advances and applications of immune receptor sequencing in systems immunology. Current Opinion in Systems Biology 1: 62-68. DOI: https://doi.org/10.1016/j.coisb.2016.12.009

Looney TJ, Lee J-Y, Roskin KM, Hoh RA, King J, Glanville J, Liu Y, Pham TD, Dekker CL, Davis MM, Boyd SD. 2016. Human B-cell isotype switching origins of IgE. The Journal of Allergy and Clinical Immunology 137: 579-586.. DOI: https://doi.org/10.1016/j.jaci.2015.07.014, PMID: 26309181

Lunter G, Goodson MS. 2011. Stampy: a statistical algorithm for sensitive and fast mapping of Illumina sequence reads. Genome Research 21: 936-939. DOI: https://doi.org/10.1101/gr.111120.110, PMID: 20980556

Mandric I, Rotman J, Yang HT, Strauli N, Montoya DJ, Van Der Wey W, Ronas JR, Statz B, Yao D, Petrova V, Zelikovsky A, Spreafico R, Shifman S, Zaitlen N, Rossetti M, Ansel KM, Eskin E, Mangul S. 2020. Profiling immunoglobulin repertoires across multiple human tissues using RNA sequencing. Nature Communications 11: 3126. DOl: https://doi.org/10.1038/s41467-020-16857-7, PMID: 32561710

Meyts I, Bossuyt X, Proesmans M, De B. 2006. Isolated IgG3 deficiency in children: to treat or not to treat? Case presentation and review of the literature. Pediatric Allergy and Immunology 17: 544-550. DOI: https://doi.org/ 10.1111/j.1399-3038.2006.00454.x, PMID: 17014632

Mroczek ES, Ippolito GC, Rogosch T, Hoi KH, Hwangpo TA, Brand MG, Zhuang Y, Liu CR, Schneider DA, Zemlin M, Brown EE, Georgiou G, Schroeder HW Jr. 2014. Differences in the composition of the human antibody repertoire by b cell subsets in the blood. Frontiers in Immunology 5: 96. DOI: https://doi.org/10. 3389/fimmu.2014.00096, PMID: 24678310

Ostmeyer J, Christley S, Rounds WH, Toby I, Greenberg BM, Monson NL, Cowell LG. 2017. Statistical classifiers for diagnosing disease from immune repertoires: a case study using multiple sclerosis. BMC Bioinformatics 18: 401. DOl: https://doi.org/10.1186/s12859-017-1814-6, PMID: 28882107

Pedregosa F. 2015. Machine Learning in Python. Journal of Machine Learning Research: JMLR 12: 2825-2830.

R Development Core Team. 2018. A Language and Environment for Statistical Computing. R Foundation for Statistical Computing. https://www.R-project.org

Rubelt F, Bolen CR, McGuire HM, Vander Heiden JA, Gadala-Maria D, Levin M, Euskirchen GM, Mamedov MR, Swan GE, Dekker CL, Cowell LG, Kleinstein SH, Davis MM. 2016. Individual heritable differences result in unique cell lymphocyte receptor repertoires of naïve and antigen-experienced cells. Nature Communications 7 : 11112. DOI: https://doi.org/10.1038/ncomms11112, PMID: 27005435 
Shemesh O, Polak P, Lundin KEA, Sollid LM, Yaari G. 2021. Machine Learning Analysis of Naïve B-Cell Receptor Repertoires Stratifies Celiac Disease Patients and Controls. Frontiers in Immunology 12: 627813. DOI: https:// doi.org/10.3389/fimmu.2021.627813, PMID: 33790900

Stavnezer J, Guikema JEJ, Schrader CE. 2008. Mechanism and Regulation of Class Switch Recombination. Annual Review of Immunology 26: 261-292. DOI: https://doi.org/10.1146/annurev.immunol.26.021607.090248, PMID: 18370922

Tonegawa S. 1983. Somatic generation of antibody diversity. Nature 302: 575-581. DOI: https://doi.org/10. 1038/302575a0, PMID: 6300689

Vander Heiden JA, Yaari G, Uduman M, Stern JNH, O'Connor KC, Hafler DA, Vigneault F, Kleinstein SH. 2014. PRESTO: a toolkit for processing high-throughput sequencing raw reads of lymphocyte receptor repertoires. Bioinformatics 30: 1930-1932. DOl: https://doi.org/10.1093/bioinformatics/btu138, PMID: 24618469

Venables WN, Ripley BD. 2002. Modern Applied Statistics with S. Springer. DOI: https://doi.org/10.1007/978-0387-21706-2

Vidarsson G, Dekkers G, Rispens T. 2014. IgG subclasses and allotypes: from structure to effector functions. Frontiers in Immunology 5: 520. DOI: https://doi.org/10.3389/fimmu.2014.00520, PMID: 25368619

Wesemann DR, Magee JM, Boboila C, Calado DP, Gallagher MP, Portuguese AJ, Manis JP, Zhou X, Recher M, Rajewsky K, Notarangelo LD, Alt FW. 2011. Immature B cells preferentially switch to IgE with increased direct $\mathrm{S} \mu$ to $\mathrm{S}_{\varepsilon}$ recombination. The Journal of Experimental Medicine 208: 2733-2746. DOI: https://doi.org/10. 1084/jem.20111155, PMID: 22143888

Wu YC, Kipling D, Leong HS, Martin V, Ademokun AA, Dunn-Walters DK. 2010. High-throughput immunoglobulin repertoire analysis distinguishes between human IgM memory and switched memory B-cell populations. Blood 116: 1070-1078. DOI: https://doi.org/10.1182/blood-2010-03-275859, PMID: 20457872

Yaari G, Uduman M, Kleinstein SH. 2012. Quantifying selection in high-throughput Immunoglobulin sequencing data sets. Nucleic Acids Research 40: e134. DOI: https://doi.org/10.1093/nar/gks457, PMID: 22641856

Ye J, Ma N, Madden TL, Ostell JM. 2013. IgBLAST: an immunoglobulin variable domain sequence analysis tool. Nucleic Acids Research 41: W34-W40. DOI: https://doi.org/10.1093/nar/gkt382

Zhang K, Mills FC, Saxon A. 1994. Switch circles from IL-4-directed epsilon class switching from human B lymphocytes Evidence for direct, sequential, and multiple step sequential switch from mu to epsilon Ig heavy chain gene. Journal of Immunology 152: 3427-3435 PMID: $8144926 .$,

Zheng NY, Wilson K, Jared M, Wilson PC. 2005. Intricate targeting of immunoglobulin somatic hypermutation maximizes the efficiency of affinity maturation. The Journal of Experimental Medicine 201: 1467-1478. DOI: https://doi.org/10.1084/jem.20042483, PMID: 15867095 